OPEN ACCESS

Edited by:

Vivek Agarwal,

King George's Medical

University, India

Reviewed by:

Nidhi Chauhan,

Govt. Medical College and

Hospital, India

Chhitij Srivastava,

Motilal Nehru Medical College, India

*Correspondence:

Jonathan A. Berken

jberken@/uriechildrens.org

Specialty section:

This article was submitted to

Children and Health,

a section of the journal

Frontiers in Pediatrics

Received: 07 February 2021 Accepted: 22 March 2021

Published: 14 April 2021

Citation:

Berken JA, Heard-Garris N and Wakschlag LS (2021) Guardians at the Gate: Early Adversity, Neurocognitive

Development, and the Role of the

Pediatrician in the Era of COVID-19.

Front. Pediatr. 9:665335

doi: 10.3389/fped.2021.665335

\section{Guardians at the Gate: Early Adversity, Neurocognitive Development, and the Role of the Pediatrician in the Era of COVID-19}

\author{
Jonathan A. Berken ${ }^{1,2 *}$, Nia Heard-Garris ${ }^{2,3,4}$ and Lauren S. Wakschlag ${ }^{2,5}$ \\ ${ }^{1}$ Department of Pediatrics, Ann \& Robert H. Lurie Children's Hospital of Chicago, Chicago, IL, United States, ${ }^{2}$ Institute for \\ Innovations in Developmental Sciences, Northwestern University, Chicago, IL, United States, ${ }^{3}$ Division of Academic General \\ Pediatrics, Department of Pediatrics, Ann \& Robert H. Lurie Children's Hospital of Chicago and Northwestern University \\ Feinberg School of Medicine, Chicago, IL, United States, ${ }^{4}$ Mary Ann \& J. Milburn Smith Child Health, Outreach, Research, \\ and Evaluation Center, Stanley Manne Children's Research Institute, Ann \& Robert H. Lurie Children's Hospital of Chicago, \\ Chicago, IL, United States, ${ }^{5}$ Department of Medical Social Sciences, Northwestern University Feinberg School of Medicine, \\ Chicago, IL, United States
}

Adverse childhood experiences (ACEs) profoundly impact neurocognitive development. Specifically, when these events occur during critical periods of brain plasticity, a time of significant synaptogenesis, neural pruning, and myelination, typical neurodevelopment can become derailed. Adverse childhood experiences promote morphological changes in neuronal microcircuitry which may lead to diminished cognitive flexibility, inattention, increased impulsivity, decreased school readiness, and disruptive behaviors. In this regard, the current COVID-19 pandemic represents an especially complex adverse experience that disturbs a child's social milieu and support network, likely interfering with brain maturation and executive function. Here, we take a neurodevelopmental approach to argue for the critical role that pediatricians must fulfill in mitigating the potentially detrimental consequences of COVID-19. We call for ACE screening and anticipatory guidance in the primary care setting, and the use of validated interventions and skills to bolster resilience, when ACEs are identified. We present a clinical workflow for the physician to proactively assess, identify, stratify, and address the severity of ACEs worsened by COVID-19. We discuss home-based activities and resources for children and adolescents to promote stress reduction, connectiveness, and self-awareness and create a more positive environment to maximize neurodevelopmental potential in the face of the ongoing pandemic.

Keywords: adverse child experiences, brain development, toxic stress, COVID- 19, neurocognition

\section{COMMENTARY}

Pandemics have punctuated the course of human civilization from Biblical times to the modern era. Broadly, they represent tragic milestones in history that have led to famine, war, and political upheaval. In modern times, the impact of these infectious diseases on global health has been primarily viewed in terms of their effects on adult well-being. In recent decades, however, there has been an increasing focus on the immediate and long-term risks that toxic stress, a frequent 
concomitant of pandemics, pose to the health of children, arguably the most vulnerable of all population groups $(1,2)$. To many children, the current COVID-19 pandemic represents what psychologists, pediatricians, and social service agencies refer to as an adverse childhood experience (ACE), or perhaps more fittingly, a complex of multiple adverse experiences, stemming from the restrictions imposed to mitigate the spread of the pandemic. For some children, these constraints, especially those relating to protective confinement and a lack of access to customary social outlets, are likely detrimental to physical and emotional health. For others, the challenges posed by this plague have the potential to foster greater resilience, when strong nurturing family relationships act to lessen the impact of protracted restrictions in social interaction (3). However, for those lacking such sources of support, the negative impact of the pandemic is likely to intensify, as the result of persistent isolation, stay-at-home orders, school closures, economic slowdown, parental unemployment, the death of loved ones, and separation from customary supports. Such profound changes, in the absence of compensatory factors, can result in a toxic stress response, a state of neuroendocrine dysregulation that results from prolonged exposure to adversity, threatening the future neurodevelopmental, behavioral, and emotional health of a generation of children (2, 4-6). Because the ongoing crisis has so significantly raised the stakes for our youth, especially those from low-resourced neighborhoods, it is incumbent upon pediatricians to screen for adverse conditions in a child's physical, social, and familial environment that result from or are exacerbated by this pandemic. In so doing, pediatricians become guardians at the gate, assuming a critical role in minimizing the negative consequences of COVID-19 on development, thus maintaining a child's potential to enjoy cognitive, emotional, and neuropsychological health throughout his or her life.

The current COVID-19 pandemic, while extraordinary, is one of many adverse experiences to which children might be exposed. Examples include chronic illness, poverty and malnutrition, racial discrimination, emotional neglect, physical maltreatment, institutionalization, parental mental illness and substance abuse, and exposure to domestic violence, experiences many of which are likely to increase in incidence as a result of the compounded stress experienced by parents and caregivers. At this juncture, the COVID-19 pandemic shows no sign of abating and, in fact, appears to be escalating. As the health crisis continues, its effects may manifest as a range of ACEs. In households at risk, job loss and food insecurity, coupled with the potential uptick in parental mental health instability and violence, may create a substrate for child abuse and neglect.

COVID-19 related ACEs may be superimposed upon adverse conditions that a child might already be experiencing, further exacerbating existing impediments to typical neurodevelopment (4-6). We know that critical periods of increased brain plasticity, including synaptogenesis, neuronal pruning, and myelination, occur from birth through the second decade of life. Deviations from normative experiences can derail typical

Abbreviations: ACE, adverse childhood experience. neurodevelopment, with negative behavioral sequelae (7). This is of special importance during early childhood, a period of heightened neuroplasticity, when, depending on the nature and quality of a child's experience, a "sturdy" or "fragile" foundation for lifelong health is set via consolidation of self-regulatory skills (8).

Historically, studies of ACEs have either been retrospective and focused on adult health or prospective examining the role of ACEs as predictors of developmental dysregulation and have been almost exclusively based on observations of cognitive deficits in children raised in institutionalized settings and those suffering from malnutrition or from contact with environmental hazards (7). However, many adverse experiences are more diffuse, insidious, and range in severity. These more chronic and less extreme adverse experiences are not always recognized by clinicians. In addition, children can be exposed to several different types of adversity simultaneously, both inside and outside of the home (5). Evidence suggests that each of these forms of adversity has differential effects, and that the impact of unfavorable experiences depends on the number, timing and duration of those occurrences (5). The ACEs associated with COVID-19 are particularly likely to affect children with special needs or pre-existing mental health conditions, as well as those from immigrant backgrounds or from underserved communities, populations already in need of employment, housing, and healthcare (9).

Toxic stress in children, a correlate of ACEs, results from severe, persistent adversity often along with disruptions in parental responsiveness (6). The financial and interpersonal pressures on many families brought about by the COVID-19 pandemic, and the current constraints on play and in-person school experiences, are likely to be especially detrimental for already vulnerable children.

It is now well-established that ACEs leave both a macroand microstructural footprint on the maturing brain, potentially through the development of a maladaptive neuroendocrine response of the hypothalamic-pituitary-adrenal axis (2). Studies have revealed that both ACEs and high levels of experienced stress are associated with morphological changes in neuronal microcircuitry and connectivity, especially in young children $(10,11)$. Early childhood adversity may result in significantly decreased volume of numerous brain structures, especially within the limbic system and frontal lobe, regions that continue to grow and evolve into adolescence, and that are critical to emotional regulation and executive function, as well as decreased integrity of the white matter tracts responsible for communication between these regions (11). These changes are associated with decreased cognitive flexibility and impulsivity, as well as mood and anxiety disorders. In young children, these alterations correlate with decrements in school readiness which disrupt adaptive outcomes in learning and social functioning with longlasting impact. In older children, these brain structural variations can result in inattention, impulsivity, and hyperactivity. Thus, identifying children at risk for toxic stress due to the COVID19 pandemic is critical, if effective intervention can be initiated to mitigate the risk for future neurodevelopmental problems $(6,9,11,12)$. 
In a 2012 policy statement regarding the effects of ACEs on healthy brain development, the American Academy of Pediatrics emphasized the importance of the pediatric medical home, a family-centered partnership and community-based system where medical care for infants and children is accessible, comprehensive, and compassionate. Calling for a "broad-based, multisector commitment," the authors entreated pediatricians to assume a leading role in "designing, implementing, evaluating, refining, and advocating for a new generation of protective interventions" (13), The current pandemic underscores the need for strengthening this focus, as it is likely that children and adolescents, particularly those with existing mental health issues and those from underserved and marginalized communities, will be disproportionately impacted $(11,12)$. Now, perhaps more than ever in our lifetime, children should receive special attention, most of all those who are quarantined or isolated from their parents.

Fostering a child's social, emotional, and cognitive wellbeing has the capacity to create a healthy environment that maximizes neurologic potential, physical health, and resilience. Intensive and frequent screening of families and communities will allow pediatricians to proactively assess for factors that might create stressful environments for the child during the COVID19 pandemic and beyond. The effects of chronic toxic stress in childhood are likely to be cumulative and lifelong, and if not identified and addressed, can manifest as developmental delay, poor coping skills, unhealthy lifestyles, and mental illness in childhood and adolescence. In addition, adults who experience early life stress have a greater risk of heart disease, diabetes, and substance abuse (2).

A number of well-validated inventories, based on the original ACE Study (14), have proven feasible to screen for ACEs at each well-child visit (12). Among the most promising are the Traumatic Events Screening Inventory-Child Report Form Revised (TESI-CRF-R) (13, 15), a screening tool aimed at assessing children and teens from ages 6-18 in the pediatric primary care setting, the Center for Youth Wellness ACEQuestionnaire (CYW ACE-Q Child, Teen, Teen SR) (16), and the Survey of Well-being of Young Children (SWYC) (17, 18). In order for such screening tools to be broadly useful, pediatricians must be made aware of their existence and be willing to incorporate one of these ACE questionnaires into each child's clinic visit. While these inventories are helpful, they do not replace the charge of physicians to establish a strong and supportive relationship with their patients, built on trust, mutual respect, and understanding, to elicit a detailed social history from the family, and to uncover and recognize changes in the child's mood such as increased anxiety, feelings of guilt or worthlessness, anger or hostility, or anhedonia, and somatic complaints such as muscle tension, headaches, abdominal pain, anorexia, and insomnia. It is imperative, therefore, that time for conversation, including a thorough review of systems, be integrated into each visit. In addition, physicians should screen for resilience factors and the protective aspects of their young patients' environments that can be augmented to mitigate the potential harm of ACEs (3).

Pediatricians thus play an integral role in promoting optimal neurodevelopment for children in the era of COVID-19 and thereafter. They should incorporate greater screening for adverse experiences in the primary care setting in a non-intrusive fashion, beginning with a conversation with parents or guardians about ACEs, that provides anticipatory guidance about toxic stress and its effects during the pandemic. Research suggests that these discussions are well-received, with as many as $97 \%$ of parents and guardians in one study endorsing the importance

TABLE 1 | Activities and resources for COVID-19 stress mitigation.

\begin{tabular}{|c|c|c|}
\hline Activity & Age & Description \\
\hline Routine (22) & All ages & $\begin{array}{l}\text { Promotes mental health and a sense of constancy at an uncertain time } \\
\text { (e.g., morning alarms, bedtime, meal times) }\end{array}$ \\
\hline Exercise (23) & All ages & $\begin{array}{l}\text { Helps relieve stress and emphasizes the importance of maintaining physical } \\
\text { health }\end{array}$ \\
\hline Coloring book $(24,25)$ & 1 and up & Promotes stress reduction and creativity \\
\hline Board game (26) & 3 and up & Provides opportunities for interaction with family members \\
\hline $\begin{array}{l}\text { Phone calls and video chats with } \\
\text { friends and family }(27,28)\end{array}$ & 5 and up & $\begin{array}{l}\text { Promotes connection with important social supports. Young children should } \\
\text { be supervised by caregiver }\end{array}$ \\
\hline Virtual trips (28) & 5 and up & Provides learning experience and reduces anxiety \\
\hline Simulation (28) & 5 and up & $\begin{array}{l}\text { Enacts stress-inducing scenarios to promote coping skills; the child can } \\
\text { work through a hierarchy of fears about COVID-19 }\end{array}$ \\
\hline Yoga (29) & 8 and up & Teaches relaxation techniques that help promote health and mindfulness \\
\hline Conversation starters $(22,26-28)$ & Adolescents and teenagers & $\begin{array}{l}\text { Provides prompts for difficult conversations related to the pandemic that } \\
\text { can help relieve anxiety }\end{array}$ \\
\hline Journaling (30) & Adolescents and teenagers & $\begin{array}{l}\text { Promotes reflection which helps calm anxieties and identifies emotions } \\
\text { related to COVID-19 }\end{array}$ \\
\hline $\begin{array}{l}\text { Meditation, abdominal breathing, and } \\
\text { muscle relaxation (31) }\end{array}$ & Adolescents and teenagers & $\begin{array}{l}\text { Helps bring an accepting attitude to the moment, promotes awareness of } \\
\text { one's body, and relieves stress }\end{array}$ \\
\hline
\end{tabular}

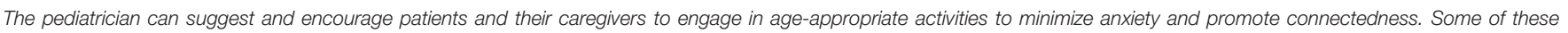
activities, including the coloring book and board game, have online versions adapted to COVID-19 which can used by parents to discuss the pandemic with their children. 


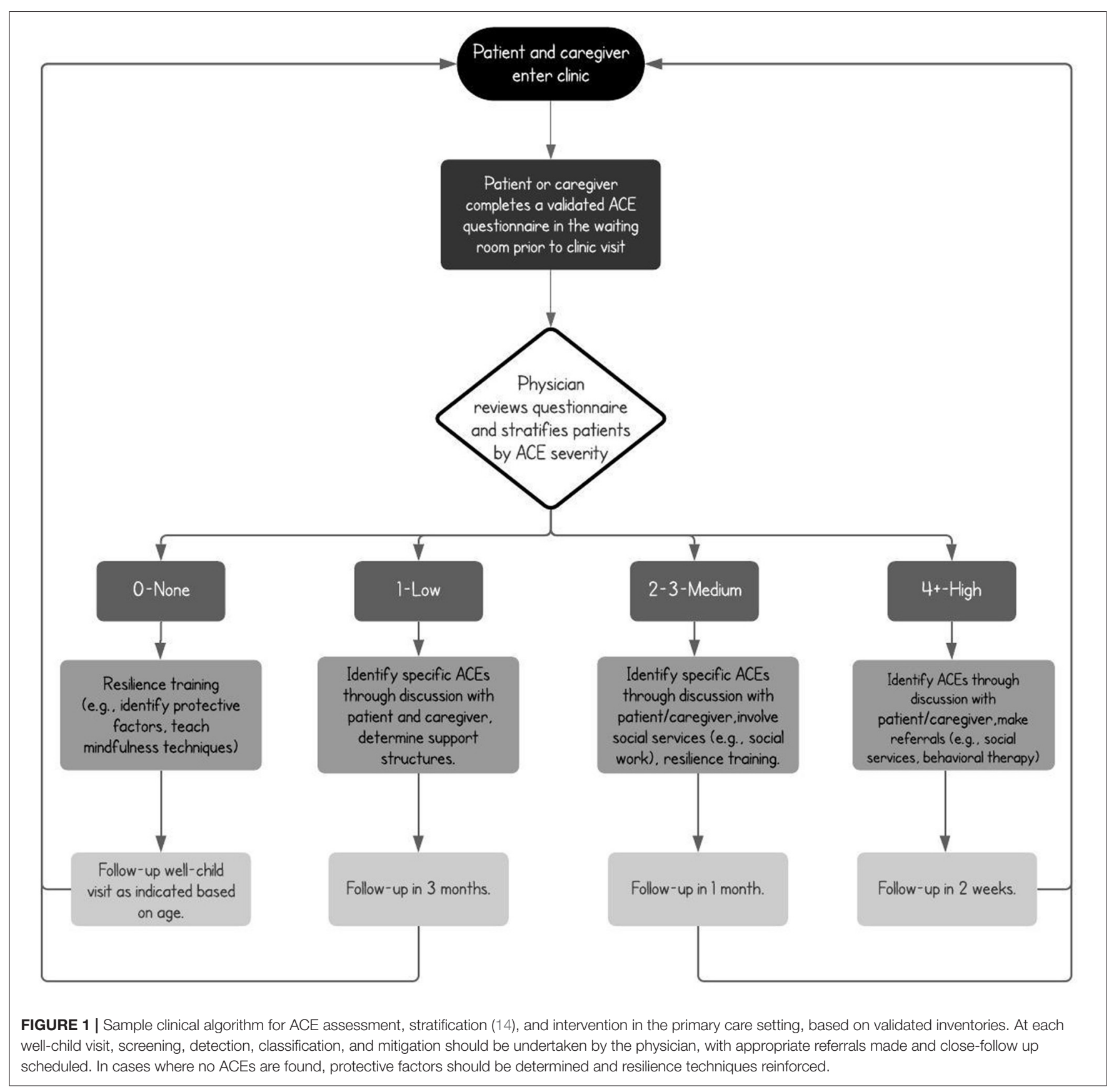

of these conversations with primary care pediatricians (19). This interaction, in addition to uncovering ACEs, can emphasize the potential for children, adolescents, and their guardians to make positive behavioral changes that foster resilience in the face of COVID-19 prohibitions. In this regard, a useful preparatory module specifically aimed at the pediatric medical provider, relating to the identification and prevention of ACEs, is available through the CDC website (20). This and similar tools, such as the Safe Environment for Every Kid (SEEK) model, address the challenges of ACEs, propose ways to approach them (21), and provide pediatricians with a better understanding of the importance of psychosocial screening in their detection and prevention.

When ACEs are documented, pediatricians should then implement patient-specific trauma-informed care, both in the clinic and through telemedicine, to address the specific stressors affecting patients and their families, including both those specifically associated with COVID-19 and those antedating the pandemic. The pediatrician should also identify activities and resources (Table 1), such as meditation and self-reflection exercises, and supports both within the family and in the community that can be enlisted to promote social connectedness 
and a more nurturing environment to mitigate a child's exposure to adversity. Some of these activities are broad and have the advantage of being already routine, familiar, and comforting for children, and have been adapted for COVID-19 by various institutions including the $\operatorname{CDC}(24,25)$, with versions that can be used by parents to help explain the pandemic. In addition, when ACEs are identified, pediatricians should increase the frequency of follow-up visits, involve community services such as social work and behavioral medicine, encourage parental participation in in-person and telephone parenting programs, and connect the families with home visiting and in-school-based interventions that cultivate positive parenting techniques and normative social behaviors, both in the home and the community (see Figure 1 for an example COVID-19 clinical workflow for primary care pediatricians based on previously validated inventories). It is important to note that the assessment of ACEs in the clinic depends on the training of pediatricians and allied healthcare professionals who should take it upon themselves to become familiar with the complexity of early life adversity and the many validated interventions that can be applied. To this effect, online modules related to the detection and prevention of ACEs and websites specifically focused on the unique stressors imposed by the pandemic should be reviewed by providers to increase comfort with existing resources (26).

At each well-child visit, parents should complete one of several short inventories, such as the Child and Youth Resilience Measure (CRYM), to help identify positive individual, familial, and community factors that promote resilience $(32,33)$. Providers should also learn and teach brief interventions that equip children with the coping skills necessary to navigate suboptimal environments. In doing so, they can emphasize

\section{REFERENCES}

1. Shonkoff JP, Gardner AS. Committee on Psychosocial Aspects of Child and Family Health; Committee on Early Childhood, Adoption, and Dependent Care; Section on Developmental and Behavioral Pediatrics. The lifelong effects if early childhood adversity and toxic stress. Pediatrics. (2012) 129:e23246. doi: 10.1542/peds.2011-2663

2. Johnson SB, Riley AW, Granger DA, Riis J. The science of early life toxic stress for pediatric practice and advocacy. Pediatrics. (2013) 13:31927. doi: 10.1542/peds.2012-0469

3. Masten AS, Barnes AJ. Resilience in children: developmental perspectives. Children (Basel). (2018) 5:98. doi: 10.3390/children5070098

4. Nelson CA, Gabard-Durnam LJ. Early adversity and critical periods: neurodevelopmental consequences of violating the expectable environment. Trends Neurosci. (2020) 43:133-43. doi: 10.1016/j.tins.2020.01.002

5. McLaughlin KA, Sheridan MA, Nelson CA. Neglect as a violation of species expectant experience: neurodevelopmental consequences. Biol Psychol. (2017) 82:462-71. doi: 10.1016/j.biopsych.2017.02.1096

6. Garner AS, Shonkoff JP. Committee on Psychosocial Aspects of Child and Family Health; Committee on Early Childhood, Adoption and Dependent Care; Section on Developmental Pediatrics. Early childhood adversity, toxic stress, and the role of the pediatrician: translating developmental science into lifelong health. Pediatrics. (2012) 129:e224-31. doi: 10.1542/peds.2011-2662

7. Anda R, Felitti V, Bremner J. The enduring effects of abuse and related adverse experiences in childhood. A convergence of evidence from neurobiology and epidemiology. Eur Arch Psychol Clin Neurosci. (2006) 256:17486. doi: 10.1007/s00406-005-0624-4 mindfulness-based mind-body techniques that reinforce how to pay attention to and accept the moment non-judgmentally through self-awareness of one's emotions, physical sensations, and thoughts $(34,35)$. They can provide resilience training, cultivated through the encouragement of safe, supportive relationships, nurturing parenting styles, household routines, and the fostering of a more positive way for children to approach adverse situations (3, 26, 33-35). As the current COVID-19 pandemic threatens to leave a harmful legacy on the neurocognitive, mental, and physical health of a generation of children, pediatricians must serve as guardians at the gate, who, with knowledge, compassion, and patience help create environments in which children will flourish.

\section{DATA AVAILABILITY STATEMENT}

The original contributions presented in the study are included in the article/supplementary material, further inquiries can be directed to the corresponding author/s.

\section{AUTHOR CONTRIBUTIONS}

$\mathrm{JB}, \mathrm{NH}-\mathrm{G}$, and LW drafted the initial manuscript, and reviewed and revised the manuscript. All authors approved the final manuscript as submitted and agree to be accountable for all aspects of the work.

\section{ACKNOWLEDGMENTS}

We gratefully acknowledge Ashley Nielsen, Ph.D. and Elizabeth S. Norton, Ph.D. for contributions to this larger body of work.

8. Shonkoff JP. From neurons to neighborhoods: old and new challenges for developmental and behavioral pediatrics. J Dev Behav Pediatr. (2003) 24:706. doi: 10.1097/00004703-200302000-00014

9. Felitti VJ, Anda RF, Nordenberg D, Williamson DF, Spitz AM, Edwards V, et al. Relationship of childhood abuse and household dysfunction to many of the leading causes of death in adults. The Adverse Childhood Experiences (ACE) Study. Am J Prev Med. (1998) 14:245-58. doi: 10.1016/S0749-3797(98) 00017-8

10. Demir-Lira ÖE, Voss JL, O’Neil JT, Briggs-Gowan MJ, Wakschlag LS, Booth JR. Early-life stress exposure associated with altered prefrontal resting-state fMRI connectivity in young children. Dev Cogn Neurosci. (2016) 19:10714. doi: 10.1016/j.den.2016.02.003

11. Shonkoff JP. Capitalizing on advances in science to reduce the health consequences of early childhood adversity. JAMA Pedatr. (2016) 170:10037. doi: 10.1001/jamapediatrics.2016.1559

12. Fegert JM, Vitiello B, Flener PL, Clemens V. Challenges and burden of the Coronavirus 2019 (COVID-19) pandemic for child and adolescent mental health: a narrative review to highlight clinical and research needs in the acute phase and the long return to normality. Child Adolesc Psychiatry Ment Health. (2020) 14:20. doi: 10.1186/s13034-020-00329-3

13. American Academy of Pediatrics. Policy Statement: early childhood adversity, toxic stress, and the role of the pediatrician: translating developmental science into lifelong health. Pediatrics. (2012) e224-31.

14. Bethell CD, Carle A, Hudziak J, Gombojav N, Powers K, Wade R, et al. Methods to assess adverse childhood experiences of children and families: toward approaches to promote child well-being in policy and practice. Acad Pediatr. (2017) 17:51-69. doi: 10.1016/j.acap.2017.04.161 
15. Choi KR, McCreary M, Ford JD. Validation of the traumatic events screening inventory for ACEs. Pediatrics. (2019) 143:e20182546. doi: 10.1542/peds.2018-2546

16. Burke Harris N, Renschler T. Center for Youth Wellness ACE-Questionnaire (CYW ACE-Q Child, Teen, Teen SR) Version 7. San Francisco, CA: Center for Youth Wellness (2015).

17. Perrin EC, Sheldrick C, Visco Z, Mattern K. The Survey of Well-being of Young Children (SWYC) User's Manual. Version 1. Boston, MA: Floating Hospital for Children at Tufts Medical Center (2016).

18. Oh DL, Jerman P, Purewal Boparai SK, Boparai SK, Koita K, Briner S, et al. Review of tools for measuring exposure to adversity in children and adolescents. J Pediatr Heal Care. (2018) 32:564-83. doi: 10.1016/j.pedhc.2018.04.021

19. Bodendorfer V, Koball AF, Rasmussen C, Klevan J, Ramirez L, Olson-Dorff D. Implementation of the adverse childhood experiences conversation in primary care. Fam Pract. (2020) 37:355-9. doi: 10.1093/fampra/cmz065

20. Help Stop Adverse Childhood Experiences (ACEs) Early - Before They Occur. Available online at: vetoviolence.cdc.gov/apps/aces-training (accessed October 20, 2020).

21. Jacob G, van den Heuvel M, Jama N, Moore AM, Ford-Jones L, Wong PD. Adverse childhood experiences: basics for the paediatrician. Paediatr Child Health. (2019) 24:30-7. doi: 10.1093/pch/pxy043

22. Support You Child and Teen's Anxiety and Stress Related to COVID-19. Available online at: Luriechildrens.org

23. Mittal VA, Firth J, Kimhy D. Combatting the dangers of sedentary activity on child and adolescent mental health during the time of COVID-19. J Am Acad Child Adolesc Psychiatry. (2020) 59:1197-8. doi: 10.1016/j.jaac.2020.08.003

24. Understanding the Coronavirus - COVID-19 Coloring Activity Book for Kids. Really Big Coloring Books. Available online at: ColoringBook.com (March 27, 2020).

25. Coronavirus Coloring Book: Epidemic Coloring Pages for Quarantine - COVID19 Creative Coloring - Slime Green. Red Ink Press.

26. Centers for Disease Control and Prevention. Helping Children Cope. Coronavirus Disease. (2019). Available online at: CDC.gov

27. Ye J. Pediatric mental and behavioral health in the period of quarantine and social distancing with COVID-19. JMIR Pediatr Parent. (2020) 3:e19867. doi: 10.2196/19867
28. Resources for Helping Kids and Parents Cope Amidst Covid-19. American Academy of Child and Adolescent Psychiatry. Available online at: https:// www.aacap.org/AACAP/Families_and_Youth/Resource_Libraries/covid-19/ resources_helping_kids_parents_cope.aspx

29. White LS. Reducing stress in school-age girls through mindful yoga. J Pediatr Health Care. (2012) 26:45-6. doi: 10.1016/j.pedhc.2011.01.002

30. Utley A, Garza Y. The therapeutic use of journaling with adolescents. $J$ Creativity Ment Health. (2011) 6:29-41. doi: 10.1080/15401383.2011.557312

31. Simkin DR, Black NB. Meditation and mindfulness in clinical practice. Child Adolesc Psychiatr Clin N Am. (2014) 23:487534. doi: 10.1016/j.chc.2014.03.002

32. Liebenberg L, Ungar M, LeBlanc JC. The CYRM-12: a brief measure of resilience. Can J Public Health. (2013) 104-35. doi: 10.1007/BF03405676

33. Iacona J, Johnson S. Neurobiology of trauma and mindfulness for children. J Trauma Nurs. (2018) 25:187-91. doi: 10.1097/JTN.00000000000 00365

34. Bethell C, Gombojav N, Sallowa M, Wissow L. Adverse childhood experiences, resilience and mindfulness-based approaches: common denominator issues for children with emotional, mental, or behavioral problems. Child Adolesc Psychiatr Clin N Am. (2016) 25:139-56. doi: 10.1016/j.chc.2015. 12.001

35. Kallapiran K, Koo S, Kirubakaran R, Hancock K. Review: effectiveness of mindfulness in improving mental health symptoms of children and adolescents: a meta-analysis. Child Adolesc Ment Health. (2015) 20:18294. doi: $10.1111 /$ camh.12113

Conflict of Interest: The authors declare that the research was conducted in the absence of any commercial or financial relationships that could be construed as a potential conflict of interest.

Copyright (c) 2021 Berken, Heard-Garris and Wakschlag. This is an open-access article distributed under the terms of the Creative Commons Attribution License (CC $B Y)$. The use, distribution or reproduction in other forums is permitted, provided the original author(s) and the copyright owner(s) are credited and that the original publication in this journal is cited, in accordance with accepted academic practice. No use, distribution or reproduction is permitted which does not comply with these terms. 